\title{
Of Barrels and Pipes: Representation-As in Art and Science
}

\author{
Roman Frigg and James Nguyen \\ Forthcoming in Otávio Bueno, Gerorge Darby, Steven French and Dean Rickles (eds.): Thinking about \\ Science, Reflecting on Art. London: Routledge, 2017.
}

\section{Introduction}

A flame is moving along a fuse. It reaches a tyre, which starts rolling down a slope. It reaches the ground and moves horizontally for a short while before it starts climbing a tilted balance, its speed being just sufficient to pass the midpoint. This tips the balance to the other side and the tyre rolls down again. After having gone up and down another smaller balance it hits a board that is tied to a ladder. The ladder falls, hitting another board, which kicks the tyre in the direction of an oil barrel on top of which there is small trolley with a burning candle. The trolley starts moving and soon gets stuck under a metal grid with sparklers, which catch fire. This lights another fuse, setting off a small firework. A spark of the firework ignites a puddle of oil, and so on.

This is the opening sequence of the 1987 film The Way Things Go by Swiss artists Fischli\&Weiss. ${ }^{1}$ In the 29 minute long film we see a seemingly endless sequence of events involving physical objects such as tires, ladders, oil barrels, shoes and soap. The events are carefully arranged and subtly calibrated. They unfold according to exceptionless laws and yet there is an element of surprise in them. The sequence of events fascinates and even creates sense of suspense about what's next (a reviewer for The Independent enthusiastically reported that watching The Way Things Go was like watching a Hitchcock film). Yet there is no purpose, no cause, no finality and no meaning to either the events themselves or to their progression. What happens is aimless and eventually pointless.

The movie is not just a piece of somewhat unusual entertainment. The title of the movie, "The Way Things Go", has an unmistakably existential ring to it and can be seen as making reference to the fate of human ambition, the purpose of social struggle, and the search for meaning in life. ${ }^{2}$ In this way the film uses the sequence of physical events to comment on the human condition. By likening life to the sequence of events in the film, it projects some of the properties of the sequence of film-events onto human life and represents the conditio humana as sequence of carefully calibrated but ultimately aimless events. ${ }^{3}$

Revert three decades. In 1953 the economists in the Central Bank of Guatemala set their Phillips-Newlyn machine (PN-machine) in motion, a system of pipes and reservoirs with water flowing through it. ${ }^{4}$ US corporation Wrigley, one of the largest buyers of Guatemalan chicle gum, had announced that it would stop imports from Guatemala in protest to a recent land reform. The economists in the Central Bank

\footnotetext{
${ }^{1}$ A sequence of the movie can be seen at https://www.youtube.com/watch? $\mathrm{v}=\mathrm{GXrRC} 3 \mathrm{pfLnE}$.

2 This is clearer in the original German title Der Lauf Der Dinge.

3 We briefly mention alternative interpretations in Section 5.

${ }^{4}$ Our discussion of the Phillips-Newlyn machine draws on our (2017). The machine can be seen in action at https://www.youtube.com/watch?v=k -uGHWz k0.
} 
were concerned about the effect that this would have on the national economy. They adjusted the machine to account for the macroeconomic conditions in Guatemala and let the machine run. They then switched the valve marked 'exports' to the 'closed' position and watch what happened. The flow marked 'income' started falling, and the water level in a tank marked 'surplus balances' rose, which in turn caused a fall in a graph marked 'interest rates'.

But how can a machine that pumps water from reservoir to reservoir provide insight into what's happening in the Guatemalan economy? The crucial factor is that the PNMachine is not just any system of pipes and reservoirs. It was built so that it implements principles of Keynesian economics if the reservoirs are interpreted as elements of an economy such as the federal reserve and privately invested savings, and the flow of water is interpreted as the flow of money through an economy. By using this machine to study economic conditions in Guatemala the economists take the machine to be a model of that economy, and the model ends up representing the Guatemalan economy as a Keynesian economy.

The PN-machine, a scientific model, and the artwork The Way Things Go have something in common: they both represent their respective targets (or subjects) as thus or so. The PN-machine represents the Guatemalan economy as a Keynesian economy and The Way Things Go represents life as sequence of carefully calibrated but ultimately aimless events. The question then is: what establishes this sort of representational relationship? More specifically: in virtue of what does a scientific model or piece of $\operatorname{art}(X)$ represent a target system or subject $(Y)$ as thus or so $(Z)$ ?

We take as our point of departure Nelson Goodman and Catherine Z. Elgin's discussions of representation-as in the context of artistic representation (Section 2). We then generalise their notion of representation-as so that it also covers scientific representations, which results in what we call the DEKI account of representation (Section 3). Throughout sections 2 and 3 we use visual art and material models as examples. We continue by indicating how the account can be generalised to apply to non-concrete models and artworks (Section 4). Our approach is premised on the proposition that representation in art and science share essential traits, namely the ones identified in DEKI. We defend this claim against the view that representation in the two domains is fundamentally different and submit that differences are ones of degree rather than kind (Section 5). We end by summing up our arguments (Section $6)$.

Two caveats are in order. First, when discussing scientific representation we mainly focus on models and only occasionally touch upon other kinds of representation (graphs and diagrams and so on). This limitation is owed to limitations of space and we do not imply that models are the only (or even most important) medium of scientific representation. Second, we only discuss models and artworks in as far as they are representational. Models can perform many functions beyond representation, and it goes without saying not all art is representational. The aim here is not to offer a general analysis of art and science; we only intend to analyse how models and works of art represent when they represent. Finally, we delve right into the account that we deem to the most promising account of representation, namely representation-as. For a review of alternative accounts of representation see our (forthcoming). 


\section{Goodman and Elgin's Analysis of Representation-As}

Goodman and Elgin's (GE's) ${ }^{5}$ notion of representation-as is composed of two essential ingredients: the distinction between something being a representation-of a $Z$ and something being a $Z$-representation, and the notion of exemplification. We discuss each of these in turn, and then explain how they combine to form the complex representational relation of representation-as. We illustrate their account with their own example of a caricature showing Winston Churchill as a bulldog.

\subsection{Representation-of and $Z$-representation}

Denotation is the two-place relation between a symbol and the object to which it applies. According to GE for $X$ to be a representation of $Y$ it is necessary (and sufficient) that $X$ denotes $Y$ because 'denotation is the core of representation' (Goodman 1976, 5). For this reason denotation is 'representation-of' (Elgin 2010, 4). ${ }^{6}$

A number of qualifications need to be added about this use of 'denotation'. First, denotation is usually restricted to language, where a name is understood as denoting its bearer. This restriction is neither essential nor helpful. Signs other than words can denote. A portrait can denote its subject; a photograph can denote its motif; and a scientific model can denote its target system. There is nothing in the notion of denotation that would restrict it to language (Elgin 1983, 19-35).

Second, even though proper names are the paradigmatic example of denoting expressions, denotation is not limited to these. Definite descriptions, proper names, indexical terms, sentences, pictures, graphs, diagrams, and many other symbols can also denote. In particular, at least according to GE, also predicates denote: they denote all the objects in its extension (Elgin 1983, 19; Goodman 1976, 19). The predicate 'red' denotes all red things and a picture of the hydrogen atom denotes all hydrogen atoms.

Viewing denotation as the core of representation may seem innocuous, but it has important consequences. If denotation is necessary for representation-of, then not all pictures represent in this way. Pictures showing Pickwick or unicorns do not denote anything simply because neither Pickwick nor unicorns exist. Such pictures are therefore not a representation-of anything.

This seems counterintuitive and invites the following objection: if we recognise a picture as portraying a unicorn, then surely it represents something, namely a unicorn. GE respond to this objection by pointing out that we are misled by ordinary language into believing that something is a representation only if there is something in the world that it represents:

\footnotetext{
${ }^{5}$ When referring to views shared by Goodman and Elgin, we use the acronym 'GE' to refer to them jointly.

${ }^{6}$ We put systematicity above grammatical correctness when we write ' $X$ is a representation-of $Y$ '. For a detailed discussion of GE's view on representation-of see (Frigg and Nguyen forthcoming).
} 


\begin{abstract}
"What tends to mislead us is that such locutions as "picture of" and "represents" have the appearance of mannerly two-place predicates and can sometimes be so interpreted. But "picture of Pickwick" and "represents a unicorn" are better considered unbreakable one-place predicates, or class terms, like "desk" and "table". [...] Saying that a picture represents a soandso is thus highly ambiguous between saying that the picture denotes and saying what kind of picture it is. Some confusion can be avoided if in the latter case we speak rather of a 'Pickwick-representingpicture' of a 'unicorn-representing-picture' [...] or, for short, of a 'Pickwick-picture' or 'unicorn-picture' [...] Obviously a picture cannot, barring equivocation, both represent Pickwick and represent nothing. But a picture maybe of a certain kind-be a Pickwick-picture [...] - without representing anything.' (Goodman 1976, 21-2, emphasis added)
\end{abstract}

This leads to the introduction of the notion of a $Z$-representation: $X$ is $Z$-representation if it portrays a $Z$, where we use $Z$ as a placeholder for the motif of a representation (for instance $Z$ = unicorn). Derivatively one can then also speak of $Z$-pictures, $Z$ statues, $Z$-paintings, and so on, to emphasise what kind of $Z$-representation one is dealing with: a $Z$-picture is a $Z$-representation that is a picture, etc.

Some Z-representations are representations of Zs: Guido Reni's Portrait of Cardinal Roberto Ubaldini is a man-picture and it denotes a man (namely Cardinal Ubaldini). It is one of GE's crucial insights that cases like these are, if not exceptions, then certainly not the rule. In fact there is a complete disconnect between what kind of representation something is and what, if anything, it is a representation-of (cf. Goodman 1976, 25-31). Zs do not have to be denoted by Z-representations and, vice versa, $Z$-representations do not have to denote $Z$ s. This is obvious enough in the case of language: the word 'sunflower' is not a sunflower-representation yet it is representation-of sunflowers (because it denotes sunflowers). The observation carries over to pictures. Adriaen Coorte's Three Medlars with a Butterfly is a butterflyrepresentation while being a representation-of the transformations of the soul; Lovis Corinth's Innocentia is a women-representation yet it represents innocence; and Sandro Botticelli's The Birth of Venus is woman-representation and it is not a representation-of anything (because the goddess Venus doesn't exist). The divorce of $Z$-representation and representation-of $Z$ is in no way an anomaly, contrived by the exalted imagination of unworldly artists. A lightening-bolt-representation denotes the fastest dog at the races without being a dog-representation; public restrooms aren't usually denoted by restroom-representations; and a map of Westeros is a territoryrepresentation without being a representation-of anything.

What does it take to be a $Z$-representation? In the case of pictorial representation this is a much-discussed issue. So-called perceptual accounts hold that a picture $X$ portrays a $Z$ if, under normal conditions, an observer would see a $Z$ in $X$ (Lopes 2004). GE take a different route and explain $Z$-representation in terms of what they call genres (Elgin 2010, 2-3; Goodman 1976, 23). ${ }^{7}$ Nothing in what follows depends on how this notion is unpacked and so we keep operating with an intuitive understanding of how pictures are categorised according to what they portray. Our preferred take on this in the context of scientific models is discussed in Section 3.

\title{
2.2 Exemplification
}

\footnotetext{
${ }^{7}$ Other options are also available. For a survey see Kulvicki (2006).
} 
An item exemplifies a property $P$ if it at once instantiates $P$ and refers to it. To instantiate $P$ without referring to it is merely to possess $P$, and to refer to $P$ without instantiating $P$ is to represent $P$ in a way other than by exemplifying it. An item that exemplifies a property is an exemplar (Elgin 1996, 171). Straightforward examples of exemplification are the sample cards supplied by commercial paint companies. These cards instantiate various colours, and refer to the colours instantiated (Elgin 2007).

Instantiation is a necessary condition for exemplification. But the converse does not hold: not every property that is instantiated is also exemplified. Exemplification is selective (Elgin 1983, 71). The chip card exemplifies redness, but not rectangularity, or being an inch long, even though it instantiates these properties. Only selected properties are exemplified. There is nothing in the nature of an object that determines the selection; no properties are intrinsically more important than others. Turning an instantiated property into an exemplified one requires an act of selection, which usually depends on the relevant context. The same sample card can exemplify rectangularity if used in geometry class. The specifics depend on the context and the case at hand. One aspect, however, is crucial: exemplars provide epistemic access to the properties they exemplify (ibid., 93). So to be exemplified a property not only has to be selected; it also has to be epistemically accessible. We say that a property that satisfies these criteria is highlighted. These considerations can be summarised in the following definition:

Exemplification: $X$ exemplifies property $P$ in a context $C$ iff

(i) $X$ instantiates $P$, and

(ii) $P$ is highlighted in $C$.

$P$ is highlighted in $C$ iff and

( $\alpha) C$ selects $P$ as a relevant property, and

( $\beta) P$ is epistemically accessible in $C$.

A sample card exemplifies, say, a certain shade of red because it instantiates it and, in the context of a paint shop, is selected as relevant and is epistemically accessible (a sample card too small to see with the naked eye would not exemplify red, nor does one that is used in a context in which colour is irrelevant).

Many works of art do not literally instantiate the properties they exemplify. Pictures and statues cannot instantiate properties like speed and elegance - after all they are made of paper or bronze. GE acknowledge this and say that these are examples of metaphorical exemplification (Elgin 1983, 81). A painting can literally instantiate the property of being grey; it can metaphorically instantiate sadness (Goodman 1976, 50 52). Metaphorically instantiated properties can be exemplified in the same way in which literally instantiated properties are: by being highlighted. In the next section we provide a development of GE's notion of metaphorical exemplification that emphasises the importance of the literally instantiated properties in grounding nonliterally instantiated, yet still exemplified, properties.

\subsection{Representation-As}

A key insight on the way to a definition of representation-as is that $Z$-representations can, and often do, exemplify properties associated with Zs. A racehorse-picture can 
(metaphorically) exemplify speed; a ballerina-statue can (metaphorically) exemplify grace and elegance; and air-crash-film can (metaphorically) exemplify engine failure. One could then say that an $X$ represents $Y$ as $Z$ if $X$ denotes $Y$ and is a $Z$-representation exemplifying certain $Z$-properties. This is on the right track, but one last step is lacking: the exemplified properties have to be imputed to $Y$. Thus we arrive at the following definition of representation-as (Elgin 2010, 10):

Representation-As (RA): $X$ represents $Y$ as $Z$ iff

(i) $X$ denotes $Y$,

(ii) $X$ is a $Z$-representation exemplifying $Z$-properties $P_{1}, \ldots, P_{n}$, and

(iii) $X$ imputes $P_{1}, \ldots, P_{n}$, or related properties, to $Y$.

Consider GE's example of a caricature representing Churchill as bulldog, where the caricature portrays Churchill as tenacious and ferocious. RA offers the following explanation of how the caricature does this. The caricature $(X)$ denotes Churchill $(Y)$. The caricature shows a bulldog $(Z)$, and hence is a bulldog-representation. The bulldog-representation (metaphorically) instantiates a host of bulldog-properties. Among these tenacity and ferocity are highlighted in the context in which the caricature is shown. Hence the caricature exemplifies tenacity and ferocity. Finally, these properties are imputed to Churchill himself.

We now see how The Way Things Go manages to represent the conditio humana as a sequence of carefully calibrated but ultimately aimless events. The film $(X)$ denotes the conditio humana (which it does mainly in virtue of its title). The film shows a burning fuse triggering a tyre to roll down a slope etc. $(Z)$, and hence is a burningfuse-tyre-rolling-down-a-slope-etc.-representation. The film metaphorically exemplifies Z-properties: the careful calibration of events and their ultimate aimlessness. Finally the movie imputes these to what it denotes, the conditio humana.

The natural suggestion would be to generalise RA to the scientific context by letting the $X$ range over scientific models, and $Y$ over their target systems, and $Z$ over the content or character of models. This points in the right direction, but conditions (ii) and (iii) need to be further developed in a number of ways to be able to account for what happens in the case of scientific models (and indeed some cases of artistic representation, as we shall see).

\section{The DEKI account}

In this section we develop our preferred account of scientific representation, which for reasons that will become clear later we call the DEKI account. ${ }^{8}$ Our account, which builds on RA, is primarily designed to handle scientific representation, but as we discuss in more detail below, the way that we develop RA into DEKI helps shedding light on artistic representation as well.

\footnotetext{
${ }^{8}$ For more details about the DEKI account see (Frigg and Nguyen 2017).
} 
The second condition of RA stipulates that $X$ be a $Z$-representation. The notion of a $Z$ representation has intuitive appeal in the case of visual representations. ${ }^{9}$ We readily categorise Pierre-Auguste Renoir's La Première Sortie as young-women-in-thetheatre-representation or a sequence of Goldfinger as car-chase-representation. But a system of pipes and reservoirs isn't classified as a Keynesian-economy-representation in the same way. On what grounds, then, is the PN-machine classified as a Keynesianeconomy-representation? And this problem is not specific to the PN-machine. Lengths of plasticine are used as models of myoglobin; oval shaped blocks of wood serve as models of ships, mice are used as models for humans; balls connected by sticks function as models for molecules; electrical circuits are studied as models of brain function; and autonomous robots are used as models for insect cognition. In virtue of what does a material object become a Z-representation? Neither reference to visual appearance nor appeal to genres explains how these objects come to function as Z-representations.

A representation, $X$, is first and foremost, an object with an associated set of properties: being such and such a size, being made out of such and such materials, and so on. The material constitution of representational vehicles matters and so we introduce a term of art to classify them; we can call them $O$-objects. As used here, ' $O$ ' is simply a specification of what kind of thing $X$ is. Derivatively we speak of $O$ properties to designate properties that $X$ has qua $O$-object. The PN-machine is a water-pipe-object and having a flow of one litre of water through a certain hose per unit of time is one of its $O$-properties. ${ }^{10}$

$O$-objects are turned into $Z$-representations by interpreting their $O$-properties in terms of $Z$-properties. In the PN-Machine the $O$-properties include the flow of water, the capacity of tanks, and so on. These are then associated with economic properties: the production flow of a commodity, and a quantity of stocks for example. More generally, let $\mathcal{O}=\left\{O_{1}, \ldots, O_{n}\right\}$ be a relevant set of $O$-properties pertaining to $X$, and let $\mathcal{Z}=\left\{Z_{1}, \ldots, Z_{n}\right\}$ be a set of relevant $Z$ properties. An Interpretation $I$ then is a bijective function $I: \mathcal{O} \rightarrow \mathcal{Z}$. If an $O$-property is quantitative (for instance, being $x$ metres long), the interpretation also contains a function associating the values of the $O$ property with the values of the corresponding $Z$-property. Hence, an object becomes a $Z$-representation when its properties are interpreted in the appropriate manner. We therefore say that a $Z$-representation is a pair $\langle X, I\rangle$, where $X$ is an $O$-object, and $I$ is an interpretation.

We now identify scientific models with $Z$-representations in the following manner: a model is a $Z$-representation where $X$ is an $O$-object that is used as the vehicle of the model in a certain context (either due to convention or the stipulation of a scientist, or group thereof) and $I$ is an interpretation. We then write $M=\langle X, I\rangle$ and also speak of a $Z$-model. So the reservoir-and-pipe system becomes a Keynesian-economyrepresentation when, in a certain context, it is used as the vehicle of the model and it

\footnotetext{
${ }^{9}$ This is not to say that this concept needs no further analysis; it's just to say that there is at least a pretheoretic intuition we can build on.

${ }^{10} X$ does not uniquely determine $O$. The PN machine could also be described as a metal and plastic object, or as post-war production object. Any property instantiated by $X$ could ground $O$.
} 
is endowed with an interpretation that maps its hydraulic properties to economic properties.

It is a deliberate choice that this definition of a model contains no reference to a target system. There are models that don't have target systems, and therefore we should distinguish between the notions of being a scientific model and being a scientific representation. Some $Z$-models are also representations of a $Z$, others aren't. The PNmachine is a representation of the Guatemalan economy. But Maxwell's aether-model is not a representation-of anything (there is no aether!) despite being an aetherrepresentation. Crucially, targetless models need not be failures. In some cases models are constructed without being intended to be representations-of systems in the world, and account of modelling that undercuts such an enterprise gets started on the wrong foot (we return to such models in Section 5, where we also give examples).

It pays noting that $O$ and $Z$, while often distinct, can coincide. In such cases the interpretation $I$ is the identity function. The architect's cardboard house is a houseobject that is used as a house-representation and when studying ships engineers often use small ship-shaped objects as ship-shaped-object-representations. Such representations are usually considered to be iconic models (Black 1962).

Models, understood as Z-representations, exemplify selected Z-properties. The PNmachine, for instance, exemplifies rising surplus balances and falling interest rates. But, just as a painting does not literally instantiate sadness, the PN-machine does not literally instantiate falling interest rates (it's a water-pipe system!). The problem is that if $O \neq Z$, then the model-object $X$ does not instantiate properties associated with $Z$, and thus cannot exemplify them. It's at this point that GE rely on the notion of metaphorical instantiation: although the painting doesn't literally instantiate sadness, it does metaphorically instantiate it, and can therefore exemplify it. GE are right in pointing out that it is not necessary that $X$ literally instantiates $P$. But rather than relying on the somewhat vague, and to some philosophically suspicious, notion of metaphorical instantiation we turn to the notion of an interpretation to define a precise sense of non-literal instantiation. Given that an interpretation establishes a one-to-one correspondence between $O$-properties and $Z$-properties it is natural to say that a model $M=\langle X, I\rangle I$-instantiates a $Z$-property $P$ iff $X$ instantiates an $O$-property $P^{\prime}$ which satisfies the following condition: $P^{\prime}$ is mapped onto $P$ under $I$ (and if the property is quantitative, the relevant value of $P^{\prime}$ is mapped onto the relevant value of $P$ ).

The introduction of $I$-instantiation specifies precisely how objects can exemplify properties they do not literally instantiate and it does so in a way that emphasises the importance of the properties literally instantiated by models (their $O$-properties) in establishing the exemplification of the relevant $Z$ properties. Exemplification of $Z$ properties only happens under an interpretation, and for this to happen a model must instantiate the relevant $O$-properties that the interpretation function takes to the exemplified $Z$-properties. Notice that all of this can be made sense of without the need to appeal to metaphorical instantiation (although those happy with the notion of metaphorical instantiation can see the notion of $I$-instantiation as regimenting how scientific models metaphorically instantiate properties: they do so in virtue of a combination of literally instantiating $O$-properties and interpretations). 
$I$-instantiated properties can be $I$-exemplified if they are $I$-instantiated and highlighted (as described in Section 2.2). The PN-machine, then, $I$-instantiates falling interest rates and commodity flows while instantiating particular meter readings and flows of water, and it $I$-exemplifies falling interest rates and commodity flows if they are $I$ instantiated and highlighted.

The next question to ask is: what makes the PN-machine represent the Guatemalan Economy? Or more generally: what makes a model, construed as a Z-representation, represent a target system as a $Z$ ? For a model to represent a target as $Z$ two further conditions have to hold. The first is that the model denote the target system (which, as we have seen in Section 2.1, can also be a type rather than a token). Denotation is the core of representation. It establishes representation-of. Nevertheless, as we have seen above, it is only necessary and not sufficient for representation-as. This is where the second condition comes into play. The basic idea is that properties exemplified by the model are imputed to the target. Imputation can be analysed in terms of stipulation. The model user may simply stipulate that the exemplified properties hold in the target system, and this is what establishes that the model represents the target as having those properties.

But the properties imputed are rarely exactly those exemplified by the model. The model could, for instance, exemplify being frictionless, but the property imputed to the target is something like 'having sufficiently low friction to be negligible in the current context'. In some cases the imputed properties could diverge significantly from those exemplified by the model. It is therefore crucial that the relation between them is articulated with precision. For this reason we build an explicit specification of how the exemplified properties are related to properties imputed into our account of scientific representation by means of a 'key'. Let $P_{1}, \ldots, P_{n}$ be the $Z$-properties exemplified by the model, and let $Q_{1}, \ldots, Q_{m}$ be the properties that the model imputes to the target ( $n$ and $m$ are positive natural numbers which can but need not be equal). Then the representation must come with a key $K$ specifying how exactly $P_{l}, \ldots, P_{n}$ are converted into $Q_{1}, \ldots, Q_{m}$. Borrowing notation from algebra (somewhat tongue-incheek) we write the key as a function $K$ taking a set of exemplified properties the arguments and mapping them onto a set of to-be-imputed properties:

$K\left(\left\{P_{1}, \ldots, P_{n}\right\}\right)=\left\{Q_{1}, \ldots, Q_{m}\right\}$.

$P$ and $Q$ properties often are different, but it's worth noting here that it needn't be the case that the $P$ properties are mapped to distinct $Q$ properties: the key can be the identity. This would allow for models to exemplify 'relevant properties' which they are hypothesised to share with their target systems, which amounts to the claims of those who defend versions of the similarity account of scientific representation (Giere 2004; 2010; Weisberg 2013). Moreover, since we place no restrictions on the sorts of properties that are exemplified, we do not rule out structural properties being exemplified and then imputed onto their target systems in virtue of hypothesising that there is some structure-preserving mapping that holds between the two (such as a homomorphism (Bartels 2006), or a partial-isomorphism (Bueno and French 2011; French 2003)).

Gathering together the pieces we have discussed yields the DEKI account of representation: 
DEKI: Let $M=\langle X, I\rangle$ be a model, where $X$ is an $O$-object that serves as the vehicle of the model and $I$ is an $O$-Z-interpretation. Let $T$ be the target system. $M$ represents $T$ as $Z$ iff all of the following conditions are satisfied:

(i) $M$ denotes $T$.

(ii) $M I$-exemplifies $Z$-properties.

(iii) $M$ comes with key $K$ associating the set $\left\{P_{1}, \ldots, P_{n}\right\}$ with a set of properties $\left\{Q_{1}, \ldots, Q_{m}\right\}: K\left(\left\{P_{1}, \ldots, P_{n}\right\}\right)=\left\{Q_{1}, \ldots, Q_{m}\right\}$.

(iv) $M$ imputes at least one of the $\left\{Q_{1}, \ldots, Q_{m}\right\}$ to $T$.

The account owes its name to the key ingredients: denotation, exemplification, keying up, and imputation. Figure 1 demonstrates how the various aspects of the account fit together.

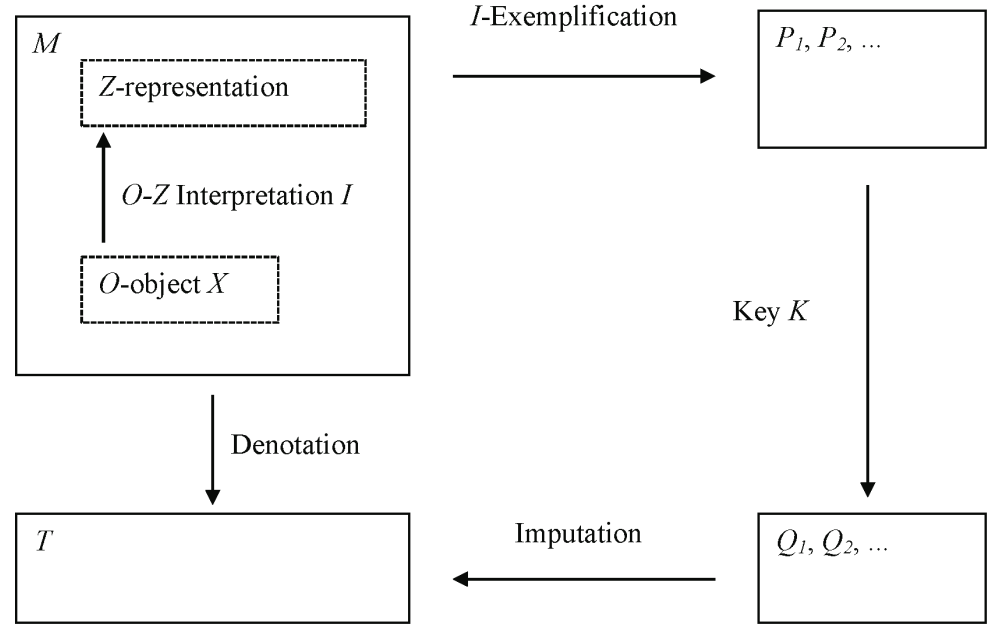

Figure 1 - The DEKI account of representation

Understanding how these conditions are met in the case of the PN-Machine illustrates how the account works. The machine $(X)$ is a water-pipe-object $(O) . Z$ is a Keynesian economy. The machine is endowed with an $O$-Z-interpretation $(I)$, mapping hydraulic properties onto economic properties. The machine so interpreted is a Keynesianeconomy-representation, and as such it is a model $M$ (a Keynesian-economy-model). The Guatemalan economists used $M$ as a representation-of the Guatemalan economy by letting the model denote the Guatemalan economy (i). They did so by borrowing the denotation of the linguistic expression 'Guatemalan economy' and the model denotes whatever the term denotes. The machine instantiates a number of water-pipeproperties and, via $I$, it $I$-instantiates a number of economy properties. Some of them the effect that a decrease in foreign exports had on income and the interest rate for instance - are exemplified because they were highlighted (ii). We can presume that the economists used an interval-valued key, which moved from specific changes in value for the interest rate in the machine before and after the change in foreign exports to values $\pm 4 \%$ around them (iii) and imputed the result to the Guatemalan economy (iv). 
The above-mentioned examples of models (the plasticine model of myoglobin, etc.) can be analysed along the same lines. ${ }^{11}$ The introduction of keys was originally motivated by maps, and maps therefore (unsurprisingly) can be analysed in terms of DEKI. A map, considered as an object, is a paper-with-colour-print-object. Under an interpretation that takes certain lines to indicate borders, blue to designate water, and black dots to signify cities the map becomes a territory-representation. Through the introduction of denotational relationships between the map and parts of the word, usually using by borrowing denotation from language (by saying that the map denotes the world, that a certain dot denotes Paris, etc.), the map becomes a representation-of the world. The map then exemplifies certain properties, for instance that the points labelled 'Paris' and 'New York' are $29 \mathrm{~cm}$ apart. The map comes with key specifying scale of the map (for instance 1:2,000,000), which translates $29 \mathrm{~cm}$ into $5800 \mathrm{~km}$. There being a distance of $5800 \mathrm{~km}$ between the two cities is then imputed to Paris and New York.

Certain measurement devices function in this way too. After a short immersion in a solution a strip of litmus paper exemplifies a certain shade of red, and, via a key that converts a colour spectrum into levels of acidity, ascribes a $\mathrm{pH}$ value of 3.5 to the solution. Some graphic representations also fit the DEKI mould. In the representation of the Madelbrod set in Argyris et al. (1994, 660), a key is used that translates colour into divergence speed (ibid., 695). The square shown is a segment of the complex plane and each point represents a complex number. This number is used as parameter value for an iterative function. If the function converges for number $c$, then the point in the plane representing $c$ is coloured black. If the function diverges, then a shading from yellow over green to blue is used to indicate the speed of divergence, where yellow is slow, green is in the middle and blue is fast.

Interpretation is crucial in visual arts too. The fact that we readily recognise Edgar Degas' Ballet Rehearsal on the Set ('Rehearsal' for short) as a ballet-representation may mask the fact that this recognition is the product of an interpretation. Symbolist painter Maurice Denis (1909/2003) famously reminded his fellow-artists that a painting, before being a battle horse, a nude, or some anecdote, is a plane surface covered with pigments. A painting per se is a welter of lines and dots, a bounded collection of curves, shapes, and colours. Assume that we make a temperature measurement at each point of a surface (for instance the bonnet of a car) and use a colour-coding similar to the one used for the Mandelbrod set to record the outcomes in the form of a plot. Further assume that it so happens that the temperature distribution is such that the resulting temperature plot is visually indistinguishable from Rehearsal. Would we say that this plot is a ballet-representation? No. A coloured surface that looks like Rehearsal is a ballet-representation only under an interpretation that takes the colours of surface to be representations of a visual experience we have when seeing ballet dancers. ${ }^{12}$

\footnotetext{
11 For want of space we cannot discuss each case individually. For useful discussions of the model of myoglobin see (de Chadarevian 2004), model of ships (Leggett 2013; Sterrett 2002), model organisms (Ankeny and Leonelli 2011), molecules (Toon 2011), brain functions (Sterratt et al. 2011), and robots (Webb 2001).

12 Explaining how this kind of interpretation works is no easy feat see Kulvicki (2006) for a useful review of the options discussed in the philosophy of art.
} 
Emphasising the importance of an interpretation in understanding a visual pattern is more than just an academic point. Much confusion can be avoided by bearing in mind that visual patterns are not 'natural' depictions of something just because they look like something, where 'natural' is taken to mean that there is some objective relation between the depiction and the depicted that does not depend in any essential way on the role of onlookers and observers. ${ }^{13}$ This point is brought home by the case of Putnam's ant, which traces a line through the sand that ends up looking like Churchill (Putnam 1981). The trace isn't a Churchill-representation, let alone a representationof Churchill, unless it's interpreted as such. And although the visual similarity between the trace in the sand and the British politician can form the basis of such an interpretation (an onlooker could interpret the shape of the trace as the shape of Churchill's face with a cigar in his mouth for example), they needn't. And without an onlooker there is no interpretation to begin with and the trace is not a $Z$-representation of any kind. ${ }^{14}$ The adoption of an interpretation is a conventional choice and $Z$ representations don't have to be objectively related, via visual similarity or otherwise, to Z's (this is not to say that there never is such connection; the point is that such a relation does not turn something into a $Z$-representation without the adoption of an appropriate interpretation).

The importance of an interpretation is highlighted by considering cases where the 'obvious' or 'natural' understanding of an image is in fact not the correct one. James Elkins discusses striking cases of such images. One of his examples is a widelyreproduced Hubble Space Telescope image of young stars in the Eagle Nebula (Elkins 2007, 10-12). We see an image that looks like an under-water photograph of a rock formation that is covered with a think layer of brownish seaweed. The unassuming onlooker is seduced into thinking that young stars in the Eagle Nebula look like seaweed-covered rock formations, and part of the popularity of such images derives from the seemingly easy visual access they provide to astronomical phenomena. But, as Elkins points out, this reading of the image is profoundly mistaken. The image was combined from thirty-two individual images taken with four different cameras. These images were cleaned, stitched together, and given false colours. The colours that appear to represent an ordinary visual impression in fact are a coding for physical properties of the objects (blue, for instance, stands for the emission of doubly ionised oxygen). Unassuming onlookers unaware of all this will radically misinterpret the image.

In better cases visual interpretations that are misleading on the surface of it at least raise interesting questions. Benoît Mandelbort (1982) presents an impressive collection of images that are the result of mathematical algorithms and colour codings of the kind described above and yet look like depictions of mountains and planets, and Michael Barnsley (1993) produced a welter of images of the same kind that look like ferns. These, and similar achievements, were hailed as the discovery of the 'fractal geometry of nature' (as Mandelbrot calls it). It is surely remarkable that fern-lookalikes can be produced by mathematical algorithms plus a colour coding scheme, but announcement of the discovery of the fractal geometry of nature may well be premature. Per se these images tell us more about an onlooker's interpretation than

\footnotetext{
13 Suárez (2003) emphasizes this in the scientific context.

14 See French (2003), Chakravartty (2001) and Bueno and French (2011) for further discussions of this thought experiment in the context of scientific representation.
} 
about nature itself. Filling the gap between appearance and an underlying mechanism has become the subject matter of the field of research known as fractal growth theory, which attempts to show that the equations generating the images can be seen as representations of real physical or biological processes and therefore the shapes seen in the computer-generated images are reflective of natural process. If true that's a significant discovery, and one that goes way beyond the superficial observation that a computer plot, when seen through a visual-image-interpretation, looks like a fern or a planet.

Returning from cautionary notes to constructive explanation, DEKI has the means to explain the working of symbolic art. Frans Pourbus the Younger's painting of Anne of Austria is, in our parlance, a Princess-with-dog-representation. The painting is also a representation-of Princess Anne, because it denotes the princess. But it is not representation-of her dog (even if she had one); the part of the painting showing a dog does not denote anything (the painting doesn't function like a portrait of a royal couple where half of the painting denotes the queen and the other half the king). But the dog is an important part of the picture and can't be dismissed as a mere ornament. The dog is exemplified. Under the conventions used at the time the dog was a symbol for fidelity, and so the painting should be read as coming with a key associating a dog with fidelity (much in the same way in which litmus paper comes with key associating the colour red with acidity). The painting then imputes the thus keyed-up property to the princess and represents her as faithful.

\section{Non-Concrete Objects}

Not all models are physical objects, and not all artworks are visible and tangible. Issac Newton's model of the sun-earth system consists of two perfect spheres with a homogeneous mass distribution gravitationally interacting with each other but nothing else, and Leonardo Fibonacci's model of a population consists of immortal rabbits reproducing indefinitely at a constant rate living in an environment that places no restrictions on either food or space. Mark Twain's The Adventures of Huckleberry Finn tells a story about Huck Finn and Tom Sawyer, two wayward boys exploring the Mississippi, and Louis-Ferdinand Céline's Journey to the End of the Night follows antihero Ferdinand Bardamu on his journeys through France and the United States.

These objects don't exist; they can't be seen; and they can't be touched. They are non-concrete objects. They are often regarded as fictional objects or characters. How to analyse such objects is a formidable philosophical problem (indeed there is a question already whether they are objects at all), and there are more options available than we can mention here. ${ }^{15}$ For our purposes it does not matter which options we choose. Since things like Huckleberry Finn and immortal rabbits are accessed through the imagination we refer to them as 'imagined-objects'. The hyphen indicates that we use this locution as a term of art whose sole purpose (in this context) is to provide us with a convenient way to talk about these things while remaining ontologically noncommittal. Imagined-objects can have properties. Bardamu is a gnome and Tom

\footnotetext{
15 For reviews of these options see Friend (2007) and Salis (2013). See also French (2010) who argues
} that we can adopt a 'quietist stance' towards the ontology of scientific models and theories. 
Sawyer is infatuated with his classmate Becky; Newton's planets are spherical and Fibonacci's rabbits are immortal. How such property attributions are analysed depends on which view of fiction one adopts. ${ }^{16}$

What matters for our current purposes is that imagined-objects can be interpreted in the same way in which material objects can be interpreted. Phillips and Newlyn interpreted the hydraulic properties of their machine as economic properties. Newton did the same in the case of his model of the solar system. The basic imagined-object of the model is the so-called two-body system: a system consisting of two perfect spheres with a homogenous mass distribution, one large and one small, attracted to each other with a $1 / r^{2}$ force. In the Newtonian model the larger sphere is interpreted as the sun, the smaller sphere as the earth, and the force as gravity. So in the context of the Newtonian model the two-body system is a solar-system-representation. The interpretation is independent from the basic imagined-object and could in principle be changed. This is what happened in the Bohr model of the atom, which uses the same imagined-entity (the two-body system) but the large ball is interpreted as a proton, the small ball as an electron, and the force as electrostatic attraction. Thus in the context of the Bohr model the two-body system is a hydrogen-atom-representation.

Some works of literature can be seen as working in the same way. George Orwell's Animal Farm tells the story of a farm that is run by the animals themselves. But the novel is not a manifesto for the self-governance of non-humans or a demonstration of the intelligence of pigs. The novel is an allegorical denunciation of Soviet-style communism as an exploitative reign of terror. The pigs are to be interpreted as the party functionaries and other animals - horses, chicken, sheep, and so on - as other segments of society; the happenings on the farm are to be interpreted as political events. Thus interpreted Animal Farm is Soviet-communism-representation. As such it need not be a representation-of any particular country or party apparatus. But in a letter to a friend Orwell described the novel as a tale against Stalin, indicating that the novel denotes Soviet Russia during the first half of the $20^{\text {th }}$ Century, and a number of characters in the novel denote concrete historical figures: the pig called Napoleon denotes Stalin, Snow Ball denotes Trotsky, Squealer denotes Molotov, etc. The plot exemplifies a number of features like power being built on a cult of personality, loyalty and hard work not being rewarded, decisions being arbitrary, and innocent creatures being sacrificed mercilessly in power games of a ruthless and selfish elite. All these are imputed (with an identity key) to Stalin and his entourage, thus providing a piercing criticism of the phoney pretensions of communism. ${ }^{17}$

Voltaire's Candide: or, Optimism tells the story of a young man, Candide, who adheres to the teachings of Professor Pangloss and believes that everything in the world is for the best. But when he starts travelling the world, experiencing hardship,

\footnotetext{
$16 \mathrm{We}$ favour an anti-realist approach to imagined-objects and analyse property attribution as pretend instantiation; see our Frigg and Nguyen (2016) for details. We emphasise that talk about imagination does not commit us to the view that thinking about models involves mental imagery; see Salis and Frigg (forthcoming).

17 An alternative analysis would take the story at face value and see the plot as an animal-farmrepresentation. The conversion of animal-farm-properties into Soviet-communism-properties would then be put into the key. We are not adjudicating between these options here. In our view it is a strength of the framework that it has the flexibility to accommodate different analyses of a work of literature.
} 
disaster and suffering, he becomes disillusioned with Pangloss' doctrines, which he comes to see as fundamentally at odds with how things are. On the face of it the book is a story about the adventures of a good-hearted but naïve traveller, and the story betrays Pangloss' optimism as a doctrine that is fundamentally at odds with the course events in the world. But we miss an important point if we stop here. Voltaire wrote the book as a response to Leibniz's doctrine that we live in the best of all possible worlds, created by a benevolent and omniscient God. In fact, Professor Pangloss is a parody of Leibniz and so we should read Professor Pangloss as denoting Leibniz. The story exemplifies there being an unbridgeable gap between optimist teachings and real-world events, denouncing the optimist doctrine as a piece of bogus philosophy. These properties are imputed to Leibniz' philosophy (again with an identity key), and Leibniz himself is portrayed as promulgator of a delusional and ultimately dishonest vision of the world.

These two examples aren't handpicked exceptions. Satirical and allegorical works can generally be interpreted in the same manner as the above, and so can fables and parables. Realist fiction also fits the mould (as we will see in the next section), and so do historical and biographical novels.

\section{Representation in Art and Science}

So far we have stressed the parallels between representation in art and science, and argued that both can be accommodated within the DEKI framework. This does not imply, however, that representations in art and science are identical in all respects. There are important differences. But these, we claim, are often differences of degree rather than kind. An exhaustive treatment of these differences is beyond the scope of this essay (arguably, any discussion of this issue will always remain open-ended) and so we concentrate on few focal issues: the role of targets, the flexibility of interpretation, and importance of rhetoric and style. To keep the discussion manageable we restrict attention to literature; similar points could be made about other art forms.

A fundamental objection to the project of drawing parallels between representation in art and science is that artistic representations have no well-defined target. Writing specifically about literary fiction, Currie notes that '[w]e have no more than the vague suggestion that fictions sometimes shed light on aspects of human thought, feeling, decision, and action' $(2016,304)$. Since we don't find real-life analogues of, say, Natasha and Pierre (in Leo Tolstoy's War and Peace) we cannot compare the novel and the world, which pulls the rug from underneath the project of likening representation in art and science, because such a comparison is a defining feature of scientific modelling.

The contrast between scientific models and literary fiction is rather less stark. First, not all scientific models have targets. There are famous failures like models involving the aether, phlogiston, Ptolemaic epicycles, steady state cosmology, and Lamarquean inheritance of acquired characteristics. But not all targetless models are remnants of failed scientific projects. Models of three-sex reproduction in population dynamics (Weisberg 2013), the $\varphi^{4}$-model in quantum field theory (Hartmann 1995, the Lorenz model of the atmosphere SSmith, 2007 \#1044), the Kac-ring model in statistical 
mechanics (Werndl and Frigg 2015), the logistic model of population growth (Hofbauer and Sigmund 1998) and baker's model in chaos theory (Frigg et al. 2016) are all models without targets. Crucially, they aren't failures. They were known all along not to have targets, and they were constructed for purposes other than the exploration of a particular target. ${ }^{18}$ Second, not all works of literature lack targets. As we have seen above, satirical novels like Animal Farm and Candide: or, Optimism can have clearly specified targets. Biographical novels like Vargas Llosa's Aunt Julia and the Scriptwriter are tales about real-world characters. Works in the tradition of social realism such as Émile Zola's Germinal and Charles Dickens' Oliver Twist offer piercing commentary on social reality and fierce criticism of poverty. Erich Maria Remarque's All Quiet on the Western Front and Kurt Vonnegut's SlaughterhouseFive are passionate denunciations of the horrors of World Wars I and II (respectively).

One may argue that the horrors of world wars or Stalin's cult of personality are too broad and unspecific to serve as targets. Maybe they are, and there is a discussion to be had about what counts as a target system and how it is delineated. But it pays noting that also in scientific contexts not all target systems are precisely circumscribed. Economic models represent general phenomena such as unemployment, inflation, business cycles, and exposure to risk; ecologists model general processes such as population growth and predator-prey dynamics; physicists model the approach to equilibrium; sociologists model social exclusion; political scientists have models of conflict resolution. None of these are specific. Hence, if there is difference in specificity between the targets of literary fiction and scientific models, then the difference seems to be one of degree rather than kind, and the dimensions along which comparisons are made is largely uncharted territory.

The grain of truth in Currie's observation is that not all novels have even a vague target. Franz Kafka's The Castle or Fyodor Dostoevsky's Crime and Punishment are not about anything in particular, at least not in any obvious way. They are not about World War II or poverty. This does not mean, however, that readers cannot take the novels to be about specific things. The plaintiff trying to manoeuvre her way through the endless and often uncooperative positions of a contorted legal system may interpret The Castle to be about her legal nightmare; and the remorseful criminal can recognise himself in Raskolnikov. The choice of target in such cases is ad hoc, and a myriad of other targets are equally possible. Readers are free to choose targets, and when they do so they can use the novel to generate insights about their chosen target. It seems to be correct to say that this kind of underdetermination of targets is more common in literature than in science, but at the same time it should be acknowledged that the phenomenon is not unheard of in science either. The harmonic oscillator is the physicist's favourite workhorse and almost anything from the atoms in the wall of a black body to insulin receptors has at some point or other been modelled as a harmonic oscillator.

A point where the difference between science and art is more pronounced is the flexibility of interpretation (in the sense of DEKI). In scientific cases the $Z$ is usually

18 It has been emphasised variously in the debate about models that models perform a number of functions other than representation. See Knuuttila (2005; 2011), Peschard (2011) Bokulich (2009) and Kennedy (2012) for a discussion. 
fixed by the context and the interpretation highly regimented. Someone who doesn't interpret the large sphere as the sun simply doesn't understand the Newtonian model. In literature there is often more flexibility. How much flexibility there is depends on the context and the genre. ${ }^{19}$ There is little flexibility in interpreting Animal Farm while there are (almost) no limits to an interpretation of The Castle. Fischli\&Weiss' film we described in the introduction also lends itself to different interpretations. We interpreted it as a conditio-humana-representation. Someone else might emphasise the borderline functionality of the arrangement and its constant risk of failure and see it as risk-representation. Feminists might point to the masculine character of the materials and see the design of the setup as a manifestation of the male preoccupation with mechanical processes; for them The Way Things Go could be a gender-ideologyrepresentation. And so on. In artistic contexts the interpretation is often deliberately left open, and coming up with an interesting interpretation is often a creative act in its own right. Such freedom is foreign to science, where interpretations are regimented and controlled.

A last point we want to consider is the importance of rhetoric and style in the presentation of a model or a work of literature. Language and rhetoric is a crucial aspect of a work of literature. We admire great authors not only for the inventiveness of their plots, but also (and sometime even more so) for their use of language, the elegance of their expressions, and the fluency of their diction. This importance of language and rhetoric, opponents of a parallelism of modelling and fiction point out, is an aspect that's entirely foreign to science. Currie submits that '[m]odels are not dependent for their value in learning on any particular formulation' (Currie 2016, 305), while formulations are crucial in literature. A recounting of the plot of Hundred Years of Solitude in the language of a seven-year-old is not the work of art that Gabriel García Márquez created.

There is no question that language and rhetoric play a different role in literature and in the presentation of scientific models, but that does not imply that models are completely independent of their formulation. Everybody who has ever spent time solving differential equations will know that the choice of the right coordinates for the description of the situation is crucial. In a recent paper discussing models (understood as imaginary entities) Vorms (2011) points out that what she calls the 'format of a representation' is crucial to the inferences scientists can draw from the model. The very same model, when presented under a different format, can yield different predictions and offer different explanations. Formulation matters. So, once again, the difference is one of degree and detail rather than kind.

\section{Conclusion}

The DEKI account of representation, building on Goodman and Elgin's notion of representation-as, highlights the commonalities between scientific and artistic representation. By understanding how each of DEKI's conditions are met we come to understand how a hydraulic system like the PN-machine can represent the Guatemalan economy as a Keynesian economy, and how a cleverly calibrated sequence of rolling tires and burning barrels can represent the conditio humana as

${ }^{19}$ See Eco $(1992 ; 1994)$ for discussions about the limits as to how literary texts can be interpreted. 
ultimately aimless. The account explains, in general, how an object $X$ represents a target $Y$ as thus or so $Z$. This is not to say that representation-as works in exactly the same way in science as in art (or even to say that it works in exactly the same way across the sciences or across the entire field of art). DEKI's conditions are stated at the appropriate level of abstraction so that they can be met in different ways in different cases, as we have discussed. But the differences that emerge in different instances, or types of instance, of representation-as depend on how the very same conditions, of denotation, exemplification, and so on, are met. We conclude by stressing that our analysis is aimed at cases of scientific and artistic representation. We don't want to claim that all scientific models, let alone works of art, play representational roles. But where they do, we hope that analysing them through the lens of DEKI will help us understand how they work.

\section{Acknowledgments}

We would like to thank Fiora Salis for helpful discussions and comments on an earlier draft. Thanks go to Otávio Bueno and Steven French for inviting us to be part of this project.

\section{References}

Ankeny, Rachel A. and Sabina Leonelli. 2011. "What's So Special About Model Organisms?" Studies in History and Philosophy of Science 42:313-23.

Argyris, John. H., Gunter Faust and Maria Haase. 1994. Die Erforschung Des Chaos: Eine Einführung Für Naturwissenschaftler Und Ingenieure. Braunschweig: Vieweg+Teubner Verlag.

Barnsley, Michael. 1993. Fractals Everywhere. Boston, Ma. : Academic Press.

Bartels, Andreas. 2006. "Defending the Structural Concept of Represenation." Theoria 21:7-19.

Black, Max. 1962. Models and Metaphors. Studies in Language and Philosophy. Ithaca, New York: Cornell University Press.

Bokulich, Alisa. 2009. "Explanatory Fictions." In Fictions in Science. Philosophical Essays on Modelling and Idealization, ed. Mauricio Suárez, 91-109. London and New York: Routledge.

Bueno, Otávio and Steven French. 2011. "How Theories Represent." British Journal for the Philosophy of Science 62:857-94.

Chakravartty, Anjan. 2001. "The Semantic or Model-Theoretic View of Theories and Scientific Realism." Synthese 127:325-45.

Currie, Greg. 2016. "Models as Fictions, Fictions as Models." The Monist 99:296310.

de Chadarevian, Soraya. 2004. "Models and the Making of Molecular Biology." In Models: The Third Dimension of Science, ed. Soraya de Chadarevian and Nick Hopwood, Stanford: Stanford University Press.

Denis, Maurice. 1909/2003. "From Gauguin and Van Gogh to Neo-Classicism." In Art in Theory 1900-2000, ed. Charles Harrison and Paul Wood, 46-51. Oxford: Maldon a.o. 
Eco, Umberto. 1992. "Interpretation and Overinterpretation." In Interpretation and Overinterpretation: Tanner Lectures in Human Values, ed. Stefan Collini, Cambridge: Cambridge University Press.

Eco, Umberto. 1994. The Limits of Interpretation. Indiana Indiana University Press. Elgin, Catherine Z. 1983. With Reference to Reference. Indianapolis Hackett.

Elgin, Catherine Z. 1996. Considered Judgement. Princeton: Princeton University Press.

Elgin, Catherine Z. 2007. "Understanding and the Facts." Philosophical Studies 132:33-42.

Elgin, Catherine Z. 2010. "Telling Instances." In Beyond Mimesis and Convention: Representation in Art and Science, ed. Roman Frigg and Matthew C. Hunter, 1-18. Berlin and New York: Springer

Elkins, James. 2007. Visual Practices across the University. München: Wilhelm Fink Verlag.

French, Steven. 2003. "A Model-Theoretic Account of Representation (or, I Don't Know Much About Art...But I Know It Involves Isomorphism)." Philosophy of Science 70:1472-83.

French, Steven. 2010. "Keeping Quiet on the Ontology of Models." Synthese 172:231-49.

Friend, Stacie. 2007. "Fictional Characters " Philosophy Compass 2:141-56.

Frigg, Roman, Joseph Berkovitz and Fred Kronz. 2016. "The Ergodic Hierarchy."

Frigg, Roman and James Nguyen. 2016. "The Fiction View of Models Reloaded." The Monist 99:TBC.

Frigg, Roman and James Nguyen. forthcoming. "Models and Representation." In Springer Handbook of Model-Based Science, ed. Lorenzo Magnani and Tommaso Bertolotti, Springer.

Frigg, Roman and James Nguyen. forthcoming. "Scientific Represenation Is Represenation As." In Philosophy of Science in Practice: Nancy Cartwright and the Nature of Scientific Reasoning, ed. Hsiang-Ke Chao, Reiss Julian and Chen Szu-Ting, New York: Springer.

Frigg, Roman and James Nguyen. 2017. "The Turning of the Valve: Representing with Material Models." Forthcoming in European Journal for Philosophy of Science.

Frigg, Roman and Fiora Salis. forthcoming. "Capturing the Scientific Imagination." In The Scientific Imagination, ed. Peter Godfrey-Smith and Arnon Levy, New York: Oxford University Press.

Giere, Ronald N. 2004. "How Models Are Used to Represent Reality." Philosophy of Science 71:742-52.

Giere, Ronald N. 2010. "An Agent-Based Conception of Models and Scientific Representation." Synthese 172:269 - 81.

Goodman, Nelson. 1976. Languages of Art. Indianapolis and Cambridge: Hacket. Hartmann, Stephan. 1995. "Models as a Tool for Theory Construction: Some Strategies of Preliminary Physics." In Theories and Models in Scientific Processes (Poznan Studies in the Philosophy of Science and the Humanities 44), ed. William E. Herfel, Wladiyslaw Krajewski, Ilkka Niiniluoto and Ryszard Wojcicki, 49-67. Amsterdam and Atlanta: Rodopi.

Hofbauer, Josef and Karl Sigmund. 1998. Evolutionary Games and Population Dynamics. Cambridge: Cambridge University Press.

Kennedy, Ashley Graham 2012. "A Non Representationalist View of Model Explanation." Studies in History and Philosophy of Science 43:326-32. 
Knuuttila, Tarja. 2005. Models as Epistemic Artefacts: Toward a NonRepresentationalist Account of Scientific Representation. PhD: University of Helsinki.

Knuuttila, Tarja. 2011. "Modelling and Representing: An Artefactual Approach to Model-Based Representation." Studies in History and Philosophy of Science 42:262-71

Kulvicki, John. 2006. "Pictorial Representation." Philosophy Compass 1:535-46.

Leggett, Don. 2013. "Replication, Re-Placing and Naval Science in Comparative Context, C. 1868-1904." British Journal for the History of Science 46:1-21.

Lopes, Dominic. 2004. Understanding Pictures. Oxford: Oxford University Press.

Mandelbrot, Benoit B. 1982. The Fractal Geometry of Nature. San Francisco: W.H.Freeman \& Co Ltd.

Peschard, Isabelle. 2011. "Making Sense of Modeling: Beyond Representation " European Journal for Philosophy of Science 1:335-52.

Putnam, Hilary. 1981. Reason, Truth, and History. Cambridge: Cambridge University Press.

Salis, Fiora. 2013. "Fictional Entities."

Sterratt, David, Bruce Graham, Andrew Gilles and David Willshaw. 2011. Principles of Computational Modelling in Neuroscience. Cambridge: Cambridge University Press.

Sterrett, Susan G. 2002. "Physical Models and Fundamental Laws: Using One Piece of the World to Tell About Another." Mind and Society 5:51-66.

Suárez, Mauricio. 2003. "Scientific Representation: Against Similarity and Isomorphism." International Studies in the Philosophy of Science 17:225-44.

Toon, Adam. 2011. "Playing with Molecules." Studies in History and Philosophy of Science 42:580-89.

Vorms, Marion. 2011. "Representing with Imaginary Models: Formats Matter." Studies in History and Philosophy of Science 42:287-95.

Webb, Barbara. 2001. "Can Robots Make Good Models of Biological Behaviour?" Behavioral and Brain Sciences 24:1033-50.

Weisberg, Michael. 2013. Simulation and Similarity: Using Models to Understand the World. Oxford: Oxford University Press.

Werndl, Charlotte and Roman Frigg. 2015. "Reconceptualising Equilibrium in Boltzmannian Statistical Mechanics

and Characterising Its Existence." Studies in History and Philosophy of Modern Physics 49:19-31. 